SOFTWOOD PULP MILLS

TERPENE EMISSIONS

SAMPLING AND GAS CHROMATOGRAPHY

ATMOSPHERIC CHEMISTRY

FOREST DECLINE

Open access manuscript version of

Environmental Pollution 79 (1993) 219-223

doi:10.1016/0269-7491(93)90093-4

\title{
Photooxidant-forming monoterpenes in air plumes from kraft pulp industries
}

Ann-Margret Strömvall and Göran Petersson

The paper is based on preceding reports in Swedish on terpenes as air pollutants and terpenes from pulp mills. 


\section{Photooxidant-forming Monoterpenes in Air Plumes from Kraft Pulp Industries}

Ann-Margret Strömvall and Göran Petersson

Department of Chemical Environmental Science

Chalmers University of Technology

41296 Göteborg, Sweden 


\begin{abstract}
Monoterpenes emitted to air from two Swedish kraft pulp mills were determined by sampling on the Tenax adsorbent followed by laboratory analysis using thermal desorption combined with high-resolution gas chromatography. The composition of the terpenes was found to be similar in the emissions from various parts of the process as well as in the mill plume. The bicyclic terpenes $\alpha$-pinene and 3-carene, originating principally from wood of Scots pine (Pinus sylvestris), predominated among the thirteen assessed hydrocarbon monoterpenes. Terpinolene was the most prominent among the particularly reactive terpenes with a lifetime in ozone-rich air of only a few minutes.

The rapid formation of photooxidants by chemical reactions of the terpenes with other components of the mill plume is discussed. It is concluded that a variety of phytotoxic photooxidants are formed which may contribute significantly to forest decline within $50 \mathrm{~km}$ of mills located along coasts.
\end{abstract}




\section{INTRODUCTION}

During the past two decades, forest decline due to air pollutants has been associated primarily with the large-scale occurrence of elevated levels of ozone in Europe (Ashmore et al., 1985) as well as the United States (Woodman and Cowling, 1987). In Scandinavia the impact of acid deposition from imported air pollutants has been emphasized.

Effects of locally high concentrations of photooxidants formed from hydrocarbons with short lifetimes in air has recieved much less attention. This applies particularly to photooxidants other than ozone. Recently, however, the importance of phytotoxic peroxides, particularly in combination with terpenes in forests, has been demonstrated (Becker et al., 1990).

With respect to the rapid formation of a variety of phytotoxic photooxidants, anthropogenic emissions of terpenes from forestry and the forest industry may be of particular importance. In previous studies, the monoterpenes emitted from mechanical pulp production (Strömvall and Petersson, 1990) and from logging operations (Strömvall and Petersson, 1991) were assessed. The kraft pulping process is the major forest industry in Scandinavia with respect to pulp production as well as quantities of terpenes released. The purpose of the present study was to determine monoterpenes in the emission plumes of kraft pulp mills in view of their potential impact on local-scale forest decline. 


\section{EXPERIMENTAL}

\section{Industrial plants}

Värö Bruk is a large kraft pulp mill owned by Södra Skogsägarna AB and located on the Swedish West Coast $50 \mathrm{~km}$ south of Göteborg. The annual production of 300000 tons of bleached pulp is based on batch digesters. The softwood species delivered from the forests of south-west Sweden are Scots pine (Pinus sylvestris) and the less terpene-rich Norway spruce (Picea abies ). Central mill facilities of interest with respect to terpene emissions include wood-yard, barking and chipping of pulpwood, wood chip piles, a saw-mill, digesters, black liquor evaporation, pulp washing, pulp bleaching and waste-water treatment. Turpentine amounting to $3 \mathrm{~kg}$ per ton of pulp is recovered from digester relief gases. The total Swedish production of kraft pulp is six million tons per year and the total turpentine recovery approaches 15000 tons per year.

Gruvöns Bruk is a 600000 ton per year kraft pulp and paper mill owned by Stora AB and located in Grums at the north-west part of the large lake Vänern, $200 \mathrm{~km}$ north of Göteborg. The pulp is produced in continuous digesters and the pulp softwood is taken from Scots pine and partly from Norway spruce grown in the region. The industrial complex includes integrated paper production plants, a saw-mill, and a birch sulphite plant, in addition to the kraft pulp mill facilities.

\section{Field sampling}

The well-known Tenax porous polymer was used for adsorption of monoterpenes. The adsorbent (0.1-0.2 ml, 60-80 mesh) was kept in glass liners fitting into the injector of the gas chromatograph used for subsequent laboratory desorption and analysis. The front end of the Tenax adsorbent layer was impregnated with sodium thiosulphate to prevent oxidation of monoterpenes during sampling of air containing ozone and other photooxidants. The adsorbent layer was also protected against light. During sampling, the glass liner was connected to an easily carried conventional air pump, permitting plumes to be followed according to changing wind direction. The precisely determined air volume was normally in the range $50-100 \mathrm{ml}$ for samples taken within the mills and $500-1000 \mathrm{ml}$ for plume samples taken outside the industries.

Plume sampling up to $40 \mathrm{~m}$ above ground was accomplished using a commercial balloon which was filled with helium in the field to a diameter of 1.2 $\mathrm{m}$. It was operated from ground by a nylon line. The adsorbent cartridge was fastened to the nylon line below the balloon and connected to the air pump carried on the ground with a polyethene tube ( $1 \mathrm{~mm}$ i.d.) attached to the nylon line. 


\section{Gas chromatography}

In the laboratory gas chromatograph (Carlo Erba), the sampled organic air pollutants were thermally desorbed at $200{ }^{\circ} \mathrm{C}$ onto the cooled (below zero) analytical fused silica column ( $25 \mathrm{~m} \times 0.33 \mathrm{~mm}$ i.d.). The stationary phase was a cross-linked methylsilicone (BP-1) and the desorption/carrier gas was helium. The chromatographic separations were achieved by raising the oven temperature $2^{\circ} \mathrm{C}$ per minute from $0^{\circ} \mathrm{C}$. Detection by flame ionization resulted in chromatograms and analytic data displayed by reporting integrators. The monoterpenes were identified from their retention data (Strömvall and Petersson, 1991).

A partly similar technique for trapping and analysis of organic air pollutants was recently tested at a Canadian kraft pulp mill (de Souza, 1988). 


\section{RESULTS}

\section{Emitted monoterpenes}

Duplicate samples of different terpene-rich gas streams from the batch kraft pulping process were taken inside the mill. In Table 1, the percentual composition of hydrocarbon monoterpenes is given for three selected representative samples. The first sample reflects streams emitted to air during chip loading and steam pretreatment of the chips at $\sim 100^{\circ} \mathrm{C}$ before digestion. The second sample corresponds to gas streams from the blow tank during blowing after completed digestion at $\sim 170^{\circ} \mathrm{C}$ maximum temperature. The third sample reflects the composition of a collected stream from several process steps related to digester loading, pulp washing and black liquor treatment. This stream was vented to air through a pipe extending above the mill. The corresponding chromatogram (Fig. 1) visualizes the monoterpene composition and the analytical separation achieved.

The most striking difference in composition between the three samples is a higher proportion of the volatile monoterpenes in the low-temperature sample and a higher proportion of the less volatile compounds in the second sample. The contents of non-volatile sesquiterpenes given below the table confirm the influence of process temperatures on the composition. Turpentine is recovered mainly from digester gases vented well before the digester has reached its maximum temperature. Its composition should therefore be intermediate with respect to the first two samples. It was early recognized that terpenes are emitted to air from a great many process steps (Tate, 1967), but the results given here indicate a uniform monoterpene composition throughout. The results also confirm previous studies (Landry et al., 1985) reporting that monoterpenes pass through the kraft pulping process essentially unchanged.

The monoterpene composition is similar to that of the emission plume from harvester processing of Scots pine in forests of the region (Strömvall and Petersson, 1991). The predominance of $\alpha$-pinene and 3-carene characterizes the terpene-rich wood from Scots pine in southern Scandinavia. These two terpenes were also early identified as the major components of Swedish kraft turpentine (Groth,1958). It should be observed, however, that the monoterpene composition is very different in wood from other European pine species as well as in other subspecies and provenances of Pinus sylvestris (Hafizoglu,1983).

The sesquiterpenes identified in the late part of the gas chromatograms were almost the same as those found in sulphate turpentine (Westfelt, 1966). Longifolene and $\alpha$-muurolene constituted $\sim 20 \%$ each of the total emitted sesquiterpene hydrocarbons.

The total contribution from Norway spruce wood to the terpene emissions to air 


\section{TABLE 1}

Percentual composition and physical data of monoterpenes (mainly from Scots pine) released to air during kraft processing of softwood ${ }^{\mathrm{a}}$.

\begin{tabular}{lccccc}
\hline & $\begin{array}{l}\text { Chip } \\
\text { preheating }\end{array}$ & $\begin{array}{l}\text { Digester } \\
\text { blow tank }\end{array}$ & $\begin{array}{l}\text { Pulping } \\
\text { emissions }\end{array}$ & $\begin{array}{c}\text { Boiling } \\
\text { point } \\
\left.I^{\circ} \mathrm{C}\right]\end{array}$ & $\begin{array}{c}\text { Lifetime }^{b} \\
50 \text { ppb } \mathrm{O}_{3} \\
\text { [min] }\end{array}$ \\
\hline tricyclene & 0.2 & 0.1 & 0.2 & 153 & inert \\
$\alpha$-thujene & 0.2 & 0.1 & 0.2 & 151 & 100 \\
$\alpha$-pinene & 51 & 41 & 46 & 156 & 200 \\
camphene & 1.2 & 1.2 & 1.1 & 158 & 1000 \\
$\beta$-pinene & 9.4 & 7.5 & 9.2 & 163 & 500 \\
myrcene & 1.2 & 1.6 & 1.0 & 167 & 20 \\
$\alpha$-phellandrene & 0.1 & 0.2 & 0.2 & 175 & 5 \\
3-carene & 31 & 39 & 34 & 170 & 200 \\
$\alpha$-terpinene & 0.1 & 0.3 & 0.3 & 177 & 1 \\
$\beta$-phellandrene & 2.0 & 1.9 & 2.1 & 172 & 100 \\
limonene & 1.8 & 3.0 & 2.5 & 176 & 50 \\
$\gamma$-terpinene & 0.3 & 0.7 & 0.6 & 183 & 20 \\
terpinolene & 0.9 & 2.5 & 2.1 & 186 & 5 \\
$p$-cymene & 0.4 & 0.9 & 0.7 & 177 & inert \\
\hline
\end{tabular}

a Värö Bruk, Sweden, February 22, 1989. The total sesquiterpene to monoterpene ratio was $0.005,0.10$ and 0.02 for the three samples.

b Estimated from reaction rate data (Atkinson et al., 1990). 


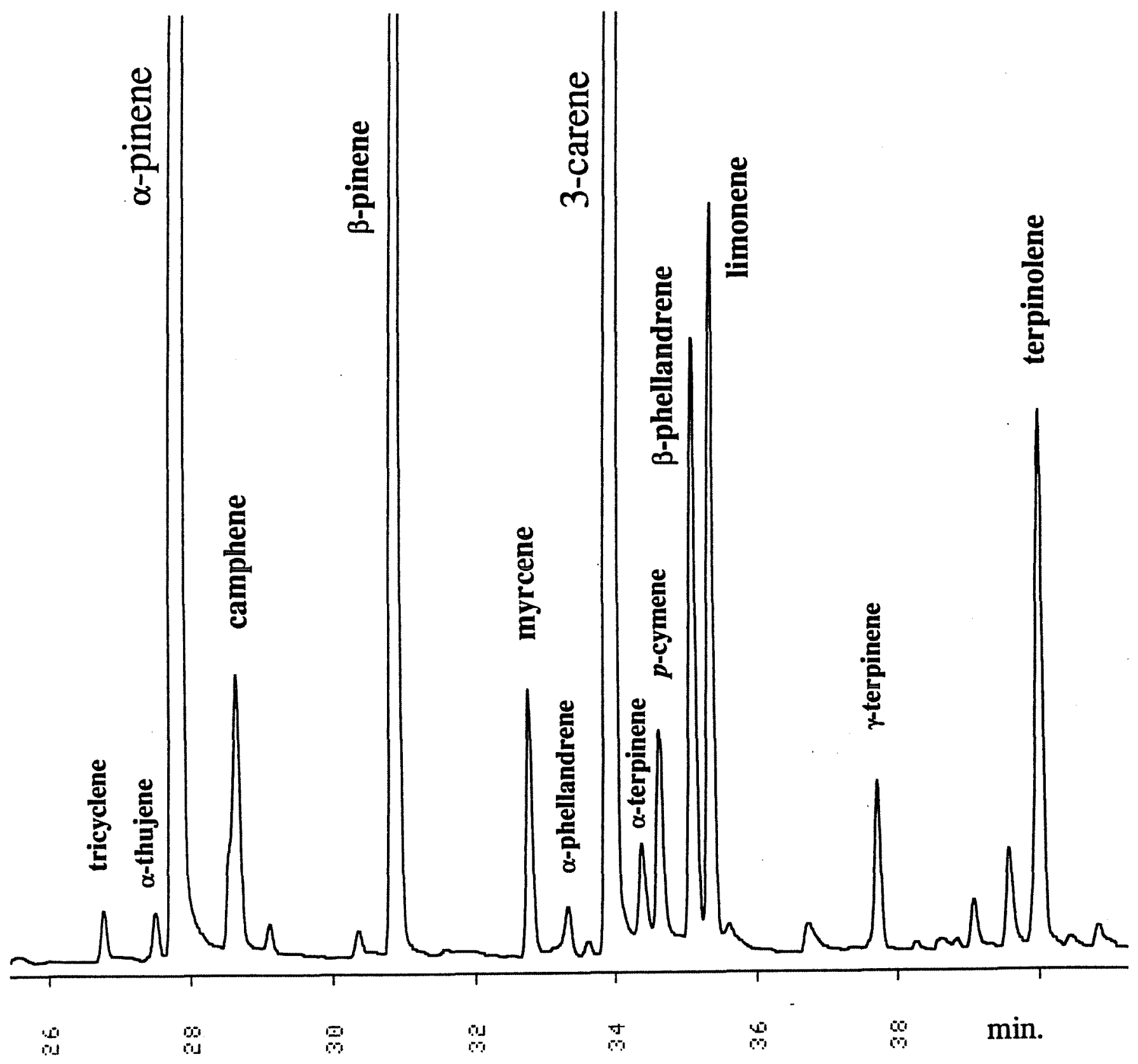

Fig. 1. Gas chromatographic separation of monoterpenes emitted to air from the kraft pulping process (Värö Bruk, Sweden, February 22, 1989). The terpenes originate mainly from wood of Scots pine. 
is estimated to be as low as $\sim 10 \%$ because of the approximately five times larger monoterpene content in Scots pine wood (Groth,1958). Quantitatively large contributions from spruce are obtained only for $\alpha$-pinene and $\beta$-pinene in the approximate ratio 2:1, as concluded from the monoterpene composition of wood of Norway spruce from the region (Strömvall and Petersson, 1990).

\section{Monoterpenes in mill plumes}

In Table 2, results are given for plume samples taken outside the two kraft mills. The specific samples reported were taken in summer mornings, when the emissions are of particular interest with respect to photooxidant formation.

The first three samples were taken in the same morning downwind from the digesters and the high venting pipe for collected terpene-rich and malodorous gas streams. The differences in composition agree surprisingly well with those reported in Table 1 for three partly corresponding process streams. The marked air stratification during sampling evidently prevented mixing of the subplumes from the mill. The fourth sample, taken with the pulping process closed down, should reflect emissions from pulpwood and wood chips at ambient temperature. The proportion of the most volatile monoterpenes is higher than in the process emissions. The fifth sample represents emissions from Gruvöns Bruk, with continuous digesters and integrated paper mills. The composition of monoterpenes is similar to that observed for Värö Bruk at ground level.

The percentual composition range, given in Table 2 for the bulk of samples, is influenced by several parameters. A large proportion of pulpwood from Norway spruce increases the proportion of $\alpha$-pinene and $\beta$-pinene and lowers the proportion of 3-carene. The content of 3-carene in Scots pine decreases from south to north in Sweden, as indicated by results for cortical oleoresin (Yazdani and Nilsson,1986). An increased proportion of northern pine wood should therefore increase the proportion of $\alpha$-pinene and decrease the proportion of 3-carene. The proportions of myrcene and especially of the monoterpenes which react still faster with ozone (Table 1) are lowered by chemical conversions in the atmosphere, particularly during the photooxidant season. 
TABLE 2

Percentual composition and total concentrations $\left(\mu \mathrm{g} / \mathrm{m}^{3}\right)$ of monoterpenes in emission plumes from kraft pulp industries, processing Scots pine and a varying proportion of the less terpene-rich Norway spruce.

\begin{tabular}{|c|c|c|c|c|c|c|}
\hline \multirow[b]{2}{*}{$\alpha$-pinene } & \multicolumn{3}{|c|}{$\begin{array}{l}\text { Värö Bruk; subplumes } \\
6 / 20 / 89 ; 0,20 \text { and } 40 m^{a}\end{array}$} & \multirow{2}{*}{$\begin{array}{l}\text { Värö } \\
6 / 1 / 90^{b} \\
57\end{array}$} & \multirow{2}{*}{$\begin{array}{l}\text { Gruvön } \\
817 / 90^{c} \\
55\end{array}$} & \multirow{2}{*}{$\begin{array}{c}\begin{array}{c}\text { Interval } \\
-40 \text { samples }\end{array} \\
40-60\end{array}$} \\
\hline & 49 & 40 & 45 & & & \\
\hline camphene & 1.8 & 1.6 & 2.5 & 2.1 & 1.5 & $1.0-2.5$ \\
\hline$\beta$-pinene & 11 & 12 & 9.3 & 13 & 9.0 & 6-15 \\
\hline myrcene & 1.2 & 0.9 & 1.3 & 0.1 & 0.6 & $0.0-2.5$ \\
\hline 3-carene & 30 & 39 & 35 & 25 & 29 & $25-40$ \\
\hline$\beta$-phellandrene & 1.9 & 2.0 & 1.8 & 0.8 & 1.3 & $0.5-2.5$ \\
\hline limonene & 2.6 & 2.6 & 3.0 & 1.1 & 2.3 & $1.0-3.0$ \\
\hline$p$ - cymene & 1.4 & 1.2 & 1.3 & 0.9 & 0.8 & $0.5-1.5$ \\
\hline total conc. & 290 & 540 & 350 & 170 & 140 & \\
\hline
\end{tabular}

a Balloon sampling at 20 and $40 \mathrm{~m}$ height, samples taken $04-05$ at sunrise $\sim 400 \mathrm{~m}$ west of the process area, ground-based inversion under clear sky, $18^{\circ} \mathrm{C}$, very weak E wind.

b Pulping process closed down, 05-07, $500 \mathrm{~m}$ downwind, cloudy, $10^{\circ} \mathrm{C}$, weak W-SW wind.

c Gruvöns Bruk, 07-09, 500 m downwind, cloudy, $15^{\circ} \mathrm{C}$, weak E-SE wind. 


\section{DISCUSSION}

\section{Total mill emissions}

The total emissions of monoterpenes to air from a Swedish kraft pulp mill as large as Värö Bruk should be in the interval 200-1500 tons per year, depending first of all on the extent of turpentine recovery and the composition of the pulpwood. An upper limit is set by the terpene content in Scots pine wood which corresponds to $\sim 5 \mathrm{~kg}$ per ton of kraft pulp for young wood (Groth, 1958) but may exceed $10 \mathrm{~kg}$ when the proportion of heartwood is high. Värö Bruk reports emissions of more than 100 tons per year from selected process streams excluding wood processing and chip storage. The turpentine recovery, approaching 1000 tons per year for Värö Bruk, is normally obtained only from digester relief gases in a batch mill. Still, the recovery tends to be much lower in mills like Gruvöns Bruk with continuous digesters. Large differences in delivered quantities between Swedish kraft mills indicate a considerable potential for increased turpentine recovery.

The characteristic nasty smell of kraft mills is due mainly to the sulphur-containing gases $\mathrm{H}_{2} \mathrm{~S}, \mathrm{CH}_{3} \mathrm{SH}, \mathrm{CH}_{3} \mathrm{SCH}_{3}$ and $\mathrm{CH}_{3} \mathrm{SSCH}_{3}$. These gases occur in the same process emissions as the terpenes. Therefore, technical efforts to decrease emissions of the malodorous gases (Burgess et al., 1984) may often be favourably combined with technical means for decreasing terpene emissions and for increasing turpentine recovery (Tate, 1967).

So far, environmental concern has applied primarily to large emissions of $\mathrm{SO}_{2}$ and $\mathrm{NO}_{\mathrm{X}}$ from the burning of spent liquor and from other mill processes and heat supply facilities. For 1989 , Värö Bruk reports over 400 tons of $\mathrm{NO}_{\mathrm{X}}\left(\right.$ as $\left.\mathrm{NO}_{2}\right)$ and 500 tons of $\mathrm{SO}_{2}$, but previous emissions have been considerably larger. Chlorine as $\mathrm{Cl}_{2}$ is still normally used, although in decreasing amounts, as one of the bleaching agents in kraft pulp mills. The annual emissions to air at a mill like Värö Bruk have been several hundred tons.

\section{Mill plume chemistry}

With respect to photooxidant formation, the reported mixture of air pollutants makes the plume of the kraft pulp mill very complex. In the central part of a $\mathrm{NO}_{\mathbf{x}}$ plume, ozone is normally depleted by its rapid reaction with NO which is converted to $\mathrm{NO}_{2}$. Similarly, the $\mathrm{HO}$ radical is scavenged by $\mathrm{NO}_{2}$ and $\mathrm{SO}_{2}$ in major reactions responsible for the formation of nitric acid and sulphate in the atmosphere. The $\mathrm{NO}_{\mathrm{x}}$ and $\mathrm{SO}_{2}$ plumes from the pulp mill are surrounded by 
subplumes of terpenes which react rapidly with atmospheric ozone (Table 1). These reactions produce Criegee biradicals, $\mathrm{HO}$ radicals, $\mathrm{HO}_{2}$ radicals and other photooxidants (Becker et al., 1990) which are mixed into the $\mathrm{NO}_{\mathrm{x}}$ and $\mathrm{SO}_{2}$ plumes to increase their photochemical activity. A further large increase in reactivity may arise from $\mathrm{Cl}$ radicals which are formed by the rapid photochemical dissociation of emitted $\mathrm{Cl}_{2}$ (Hov, 1985). As a result, the formation and deposition of nitric acid and sulphuric acid (nitrate and sulphate) is expected to occur more rapidly and more locally for a kraft pulp mill than for similar large emissions of $\mathrm{SO}_{2}$ and $\mathrm{NO}_{2}$, such as those from power plants.

During the anticyclonic periods of greatest interest with respect to photooxidant formation, the occurrence of land and sea breeze influences the behavior of the emission plumes. Most kraft pulp mills are located near the sea or large lakes where these local wind systems develop. During the night and early morning, weak winds move the air pollutants out over the water along the coast as illustrated (Fig 2.) for Värö Bruk. The first three samples reported in Table 2 were taken under such weather conditions. Already in the dark, the monoterpenes react with ozone to produce radicals and peroxides (Becker et al., 1990) as well as aldehydes (Yokouchi and Ambe, 1985). The levels of ozone are often unusually high in the lower troposphere during anticyclonic spring and summer periods. Ozone oxidizes $\mathrm{NO}$ not only to $\mathrm{NO}_{2}$ but also to $\mathrm{NO}_{3}$, which reacts to give organic nitrates of monoterpenes (Jay and Stieglitz, 1989). Furthermore, the oxidation of $\mathrm{SO}_{2}$ in the presence of ozone and monoterpenes has been demonstrated to occur in the dark (Stangl et al., 1988). Thus, the nature of monoterpenes as very reactive alkenes causes a high reactivity in the polluted air masses even before the photochemical reactions start in the morning. The efficient sunlight over the water later in the morning accelerates the reactivity of the air masses by the photolytic cleavage of $\mathrm{Cl}_{2}$, aldehydes and $\mathrm{NO}_{2}$ to produce reactive radicals and increasing amounts of peroxyacetylnitrate (PAN) and ozone. In the afternoon, the sea breeze transports the air pollutants up to $50 \mathrm{~km}$ in over land (Fig. 2).

In many respects, the air pollutants from a kraft pulp mill are similar to those studied for an industrial area in southern Norway (Hov, 1985). The circulation of pollutants with land and sea breeze and the emissions of chlorine were found to be major causes of the high local photooxidant levels recorded. In the case of a kraft pulp mill, closing down the process during periods favouring photooxidant formation might be considered. The results given in Table 2 indicate, however, that appreciable monoterpene emissions from wood and chips remain. The formation of hydrogen peroxide and organic peroxides other than PAN may even increase because of the increased proportion of hydrocarbons in relation to $\mathrm{NO}_{\mathrm{X}}$ (Becker et al., 1990). 


\section{Impact on forest decline}

The map of the coastal region around Värö Bruk (Fig. 2) marks the sea breeze zone expected to recieve particularly high levels of air pollutants originating from the emissions of the kraft mill. The air pollutants include acid deposition related to the emissions of $\mathrm{SO}_{2}$ and $\mathrm{NO}_{\mathrm{x}}$ and a variety of phytotoxic photooxidants such as ozone and PAN (Hov, 1985), hydrogen peroxide and organic peroxides (Becker $e t$ al., 1990), organic nitrates and nitro derivatives (Jay and Stieglitz, 1989) and intermediate reactive free radicals (Becker et al., 1990). It should be pointed out that the commonly measured ozone is not likely to be a good indicator either of photochemical activity (Hov, 1985) or of phytotoxicity.

The forests in the central region of the map are among those where severe decline and needle losses were first recognized in Sweden in 1983-1984. The large urban and industrial emissions from Göteborg are not likely to give rise to especially severe effects this far to the south. Therefore, the forest decline was blamed on air pollutants from Great Britain and the continent, and for several years foreign delegations were invited to see the impact of their emissions on the Swedish forests. Evidently, the previously overlooked impact of the kraft mill emissions offers a more plausible explanation for the increased forest decline in the local region. Extensive inventories of needle losses for Scots pine and Norway spruce demonstrate much less severe forest decline in the coastal region farther to the south.

It is concluded that terpene emissions in conjunction with other kraft pulping emissions contribute to aggravated forest decline particularly within distances of approximately $50 \mathrm{~km}$ from the mill. Further inventories of forest decline around kraft pulp mills may confirm their impact. It is also concluded that efforts to decrease terpene emissions from kraft mills are urgent. 


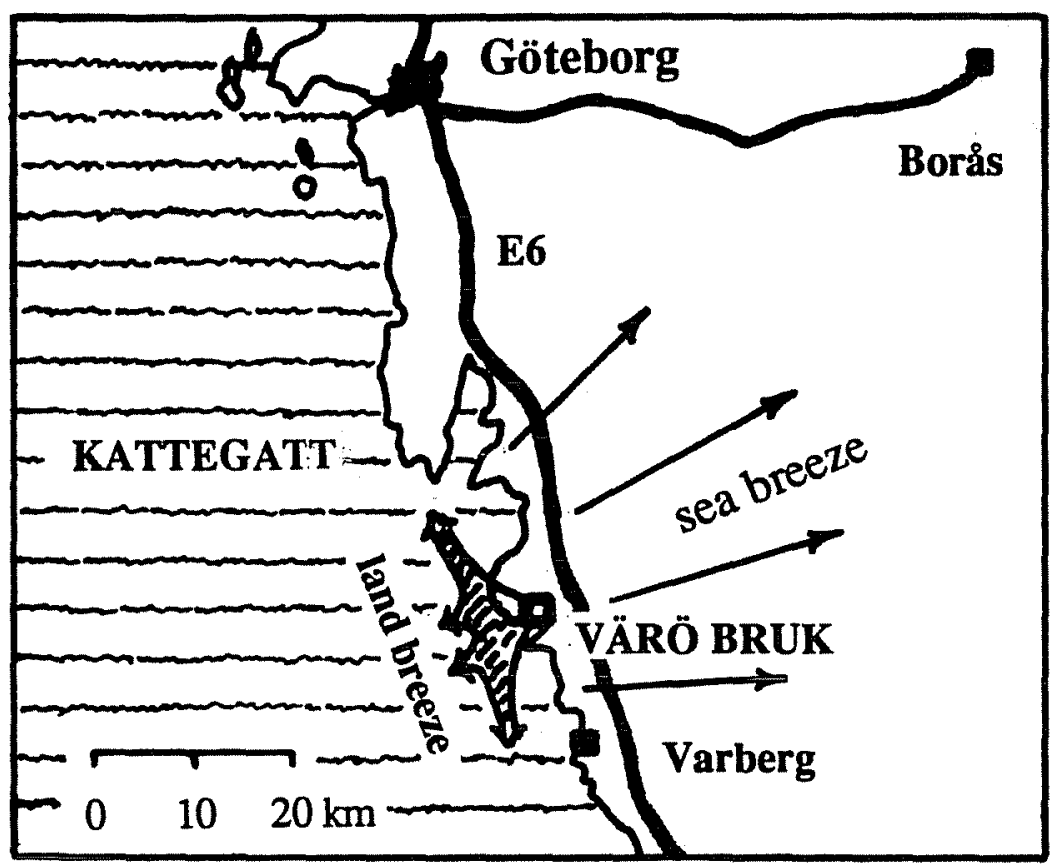

Fig. 2. Map illustrating the location of the sulphate mill Värö Bruk and the spreading of air pollutants with land breeze and sea breeze. 


\section{ACKNOWLEDGEMENTS}

The authors are grateful to The Swedish Society for Conservation of Nature for supporting the terpene research project. 


\section{REFERENCES}

Ashmore, M., Bell, N. \& Rutter, J. (1985). The role of ozone in forest damage in West Germany. Ambio, 14, 81-87.

Atkinson, R. , Hasegawa, D. \& Aschman, S.M. (1990). Rate constants for the gas-phase reactions of $\mathrm{O}_{3}$ with a series of monoterpenes and related compounds at $296^{\circ}$ K. Int. J. Chem. Kinet., 22, 871-887.

Becker, K.H., Brockman, K.J. \& Bechara, J. (1990). Production of hydrogen peroxide in forest air by reaction of ozone with terpenes. Nature, 346 , 256-258.

Burgess, T.L., Kjerulf, E.B. \& Tenn, T.I. (1984). Design considerations for high-concentration, low-volume noncondensible gas systems. Tappi, 67, 92-96.

Groth, A. B:son. (1958). Investigations on Swedish turpentine. Sven. Papperstidn., 61, 311-321.

Hafizoglu, H. (1983). Wood extractives of Pinus sylvestris L., Pinus nigra Arn. and Pinus brutia Ten. with special reference to nonpolar components. Holzforschung, 37, 321-325.

Hov, Ö. (1985). The effect of chlorine on the formation of photochemical oxidants in southern Telemark, Norway. Atmos. Environ., 19, 471-485.

Jay, K. \& Stieglitz, L. (1989). The gas phase addition of NOx to olefins. Chemosphere, 19, 1939-1950.

Landry, G.C., Rockwell, J.N. \& Steltenkamp, M.S. (1985). Analysis of mill-recovered and laboratory-recovered turpentine. Tappi, 68, 98-102.

de Souza, T.L.C. (1988). Efficient trapping of ambient organic and sulphur gases for gas chromatographic analysis. Pulp \& Pap. Can., 89, 139-144.

Stangl, H., Kotzias, D. \& Geiss, F. (1988). How forest trees actively promote acid deposition. Naturwissenschaften, 75, 42-43.

Strömvall, A.-M. \& Petersson, G. (1990). Ambient monoterpenes from stone groundwood pulp production. Holzforschung, 44, 449-452.

Strömvall, A.-M. \& Petersson, G. (1991). Conifer monoterpenes emitted to air by logging operations. Scand. J. For. Res., 6, 253-258.

Tate, D.C. (1967). Typical turpentine recovery system for batch digesters. Tappi, 50, 110A-111A.

Westfelt, L. (1966). High-boiling constituents of Swedish sulphate turpentine. Acta Chem. Scand., 20, 2841-2851.

Woodman, J.N. \& Cowling, E.B. (1987). Airborne chemicals and forest health. Environ. Sci. Technol., 21, 120-126.

Yazdani, R. \& Nilsson, J.-E. (1986). Cortical monoterpene variation in natural populations of Pinus sylvestris in Sweden. Scand. J. For. Res., 1, 85-93.

Yokouchi, Y. \& Ambe, Y. (1985). Aerosols formed from the chemical reaction of monoterpenes and ozone. Atmos. Environ., 19, 1271-1276. 